\title{
EXPERIMENTAL STUDY OF MICROWAVE SLOW WAVE COMB AND CERAMIC APPLICATORS FOR SOIL TREATMENTAT AT FREQUENCY 2.45 GHZ
}

G. Brodie and G. Torgovnikov

\author{
University of Melbourne, 4 Water St, Creswick, Victoria 3363, Australia; \\ e-mail: grigori@unimelb.edu.au
}

Keywords: ceramic applicator, comb applicator, microwave, slow wave, soil microwave treatment

\begin{abstract}
In many cases in industry it is required to heat or treat surface layers of different material (soil, timber, concrete, plastics and so on) with microwaves (MW). Traditional MW irradiators (antennas) cannot provide heating only to the surface areas and energy penetrates deep into the material, where it decays exponentially due to normal attenuation. To reduce energy losses it was required to develop special MW applicators for surface treatment to increase process efficiency. To address this problem, a slow wave ("surface wave") comb and ceramic applicators were designed, built and studied. The main property of slow waves is that the energy concentration is very near impedance electrode - comb or ceramic plate surface. Comb and ceramic slab applicators for frequency $2.45 \mathrm{GHz}$ operation were designed for the soil treatment and studied using soil with moisture content range $32-174 \%$ and density range $590-1070 \mathrm{~kg} / \mathrm{m}^{3} .30 \mathrm{~kW}$ MW plant was used for experiments.
\end{abstract}

Results of the experiments showed that a ceramic applicator provides better uniformity of energy distribution across the width of the applicator. It reduces overheating of the soil surface and energy losses. The depth of energy penetration provided by ceramic applicator is lower compared with the comb applicator. It means that the ceramic applicator provides better energy localization and more energy absorption in the soil surface layers compared with the comb applicator. The ceramic applicator is more effective for MW treatment of the soil surface areas and is recommended for practical use in machines for thermal treatment and sterilization of surface layers of the soil and other materials.

\section{Introduction}

Traditional MW irradiators (antennas) cannot provide heating only to the surface areas and energy penetrates deep into the material, where it decays exponentially due to normal attenuation. Therefore, energy losses are very significant when heating depth of $20-40 \mathrm{~mm}$ (for example to heat soil for killing weed seeds) is all that is required. Therefore, it is required to develop special MW applicators for surface treatment to increase process efficiency.

To address this problem, a slow wave (which is sometimes called a "surface wave" applicator) comb and ceramic structures, were studied. The main property of slow waves is that the energy concentration is very near impedance electrode - comb or ceramic plate surface. Previously, slow wave structures (SWS) were used mostly as delay lines [4] and as interaction circuits in MW vacuum devices, and their properties were explored only for these specific applications [3]. Extending MW technologies to industry, medicine, and army initiated a study of slow wave structures, properties and peculiarities which can be used for developing novel technologies for industrial, medical, domestic and military applications [1], [5]. It was shown by the full-wave analysis, as well as by experiments, and practical 
realization that the SWSs have many previously unknown peculiarities, which can be used for creating novel technologies for domestic and industrial heating, plasma generating, etc. The work objectives of this study were:

1. design slow wave, ceramic and comb structure applicators for soil treatment at frequency $2.45 \mathrm{GHz}$;

2. experimentally study the energy distribution from slow wave applicators in the soil;

3. examine opportunities to use slow wave structures for surface soil layer heating; and

4. recommendations for practical use of new slow wave applicators.

\section{Applicators design}

On the base of the theoretical study [2] and computer modelling slow wave comb and ceramic slab applicators for frequency $2.45 \mathrm{GHz}$ were designed. Comb applicator made from aluminium and ceramic applicator made from alumina are shown in Fig 1. Main dimensions of comb and ceramic applicators are displayed in Table 1.

Table 1. Applicator parameters.

\begin{tabular}{|l|c|c|}
\hline Parameters & Comb, mm & Ceramic, $\mathrm{mm}$ \\
\hline Working length & 356 & 356 \\
\hline Applicator body thickness & 23 & 23 \\
\hline Applicator body width & 150 & 150 \\
\hline Comb electrode width & 100 & 100 \\
\hline Ceramic slab width & 16 & 13 \\
\hline Comb electrode thickness & 185 & \\
\hline Ceramic slab thickness & $13 / 3$ & \\
\hline $\begin{array}{l}\text { Comb electrode conic part } \\
\text { length }\end{array}$ & 3 & $\begin{array}{c}\text { Alumina slab (DC=9.8, } \\
\text { loss tangent 0.0002) }\end{array}$ \\
\hline Grove depth/ width & Aluminium & \multicolumn{2}{|c|}{$0.0002)$} \\
\hline Comb tooth thickness & $\begin{array}{l}\text { Alumina (99\%) ceramic plate size 3x84x146 } \\
\text { mm (4 pieces), (DC=9.8, loss tangent }\end{array}$ \\
\hline $\begin{array}{l}\text { Material } \\
\text { Ceramic plates covering } \\
\text { comb and ceramic slab }\end{array}$ & \multicolumn{2}{|c|}{} \\
\hline
\end{tabular}

In experiments the comb and ceramic slab (Fig. 1) surfaces were covered by $3 \mathrm{~mm}$ thickness alumina plates. 


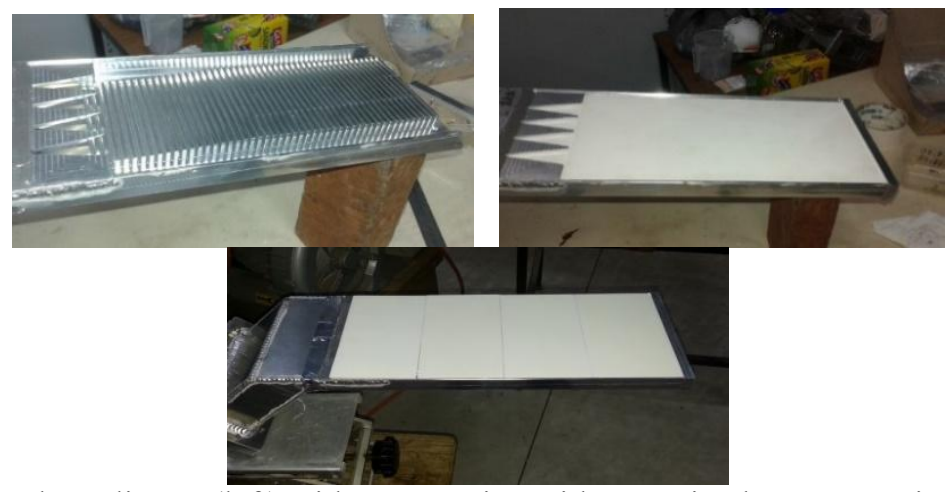

Fig. 1. Comb applicator (left) without covering with ceramic plates. Ceramic applicator (middle) without covering by ceramic plates. Comb and ceramic applicators view (right) covered by ceramic plates $(3 \times 84 \times 146 \mathrm{~mm}-4 \mathrm{pc})$.

In experiments a ceramic block made from alumina was inserted into the applicator body instead of aluminium comb electrode. The ceramic block (13 mm thickness) with $3 \mathrm{~mm}$ thickness ceramic plates formed ceramic part of the applicator with thickness $16 \mathrm{~mm}$.

\section{Experimental study. Material and methods.}

\section{Material}

The soil "Potting Mix Hortico" was used for tests. The soil had 3 different moisture contents (MC) and densities:

$\mathrm{MC}=32 \%$, density $=586 \mathrm{~kg} / \mathrm{m}^{3}$,

$\mathrm{MC}=89 \%$, density $=710 \mathrm{~kg} / \mathrm{m}^{3}$,

$\mathrm{MC}=174 \%$, density $=1070 \mathrm{~kg} / \mathrm{m}^{3}$.

The soil (mixture of organic and mineral substances) used in experiments had significant percentage of organic particles of different sizes (wood, bark, grass) therefore dielectric parameters of the soil at frequencies $2.45 \mathrm{GHz}$, temperatures from 15 to $80^{\circ} \mathrm{C}$ were in the range: dielectric constant - from 4 to 19 and loss tangent - from 0.2 to 0.3 . Only the most significant properties for $\mathrm{MW}$ heating of soil: moisture content and density were measured. The soil was placed into polypropylene containers (Fig.2) with sizes 160x250x300 mm.

\section{Experimental installation and procedure}

MW plant $30 \mathrm{~kW}(2.45 \mathrm{GHz})$ was used for experiments (Fig. 2). The applicator was connected to the MW generator by waveguides and placed into the metal box 400x500x1120 $\mathrm{mm}$ for leakage protection. Position of the container with soil on the applicator is shown in Fig. 2 (middle). Auto tuners used in MW systems provided good matching for the generator and applicators (with soil) practically without power reflection. 


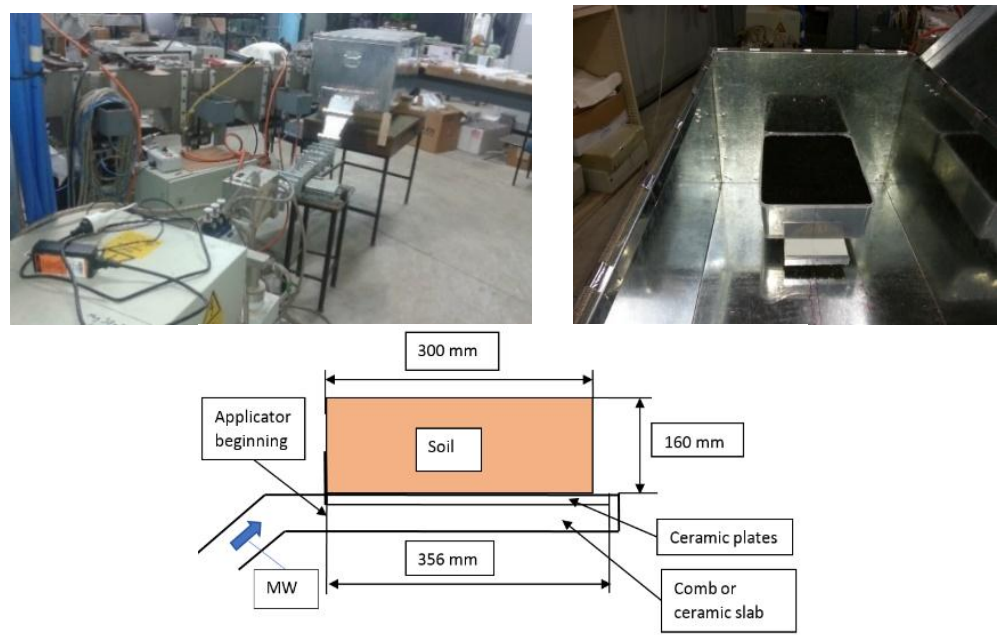

Fig 2. Applicator (in metal box) connection with $30 \mathrm{~kW} \mathrm{MW} \mathrm{generator,} 2.45 \mathrm{GHz}$ (left).

Container with soil on the applicator inside of the metal box (middle). Scheme of applicator with soil in the container (right).

Temperatures in the soil were measured by thermocouples after MW heating on the depth $10,30,50,80,100$ and $140 \mathrm{~mm}$ along applicator at distances from applicator beginning 30, $60,90,120,150,180,210,240,270$ and $350 \mathrm{~mm}$, and across the applicator in the central vertical plane and at distances from central vertical plane $37.5,75$, and $112.5 \mathrm{~mm}$ in both cross directions. Distribution of measuring points covered all volume of the soil along and across the soil samples. Scheme of container with soil position on applicator is shown in Fig.2. Lay-on jig was used for thermocouples positioning during measurements. To get reliable results of MW heating at every soil moisture content four repeats were performed. MW power of $3.5 \mathrm{~kW}$ was applied to the soil for $15 \mathrm{sec}$ and after that the temperatures were measured by thermocouples. Energy applied to the soil during experiments was 53 $\mathrm{kJ}$.

\section{Results and discussion}

\section{Temperature distribution in the soil by comb applicator}

We assume that the temperature distribution in the soil reflects energy release in different spots of the soil volume and allows assessment of the energy distribution by MW applicators. Fig. 3 shows typical temperature distribution in the soil volume at the depth of $10 \mathrm{~mm}$ by comb applicator after applying MW power $3.5 \mathrm{~kW}$ for $15 \mathrm{sec}$. 


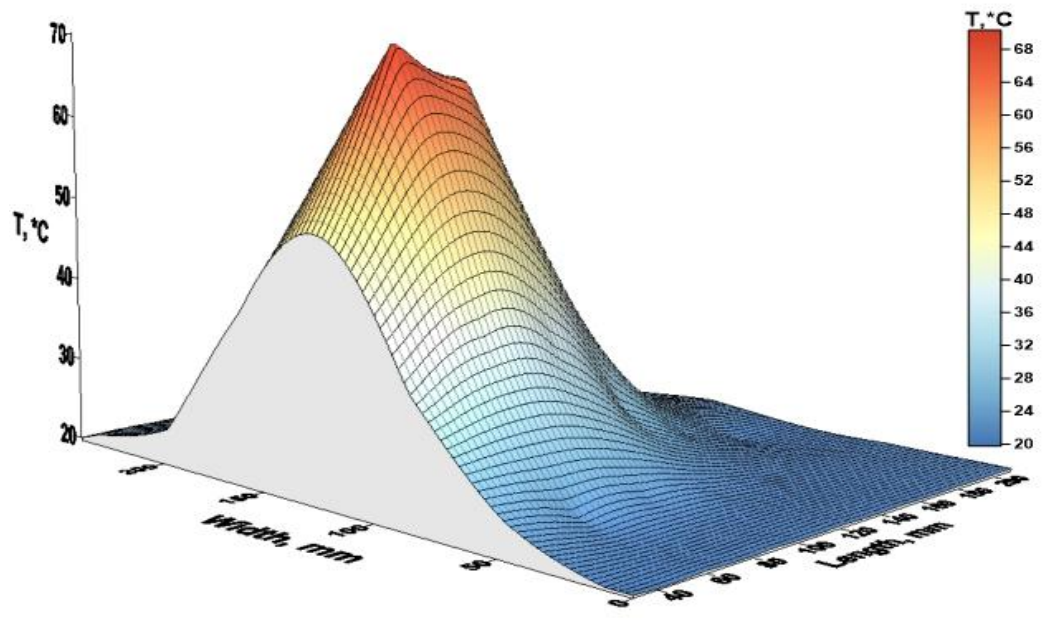

Fig. 3. Temperature distribution in the soil at the depth of $10 \mathrm{~mm}$ by comb applicator at $\mathrm{F}=2.45 \mathrm{GHz}, \mathrm{P}=3.5 \mathrm{~kW}$, time of $\mathrm{MW}$ heating $15 \mathrm{sec}$, To $=20^{\circ} \mathrm{C}$, applied energy $53 \mathrm{~kJ}$. Soil moisture content $\mathrm{MC}=89 \%$, density $710 \mathrm{~kg} / \mathrm{m}^{3}$.

Temperature distribution in the soil along the comb applicator central vertical plane for soil with $\mathrm{MC}=174 \%$, initial temperature $\mathrm{To}=20^{\circ} \mathrm{C}$, power $\mathrm{P}=3.5 \mathrm{~kW}$, duration of $\mathrm{MW}$ heating $15 \mathrm{sec}$ is shown in Fig. 4.

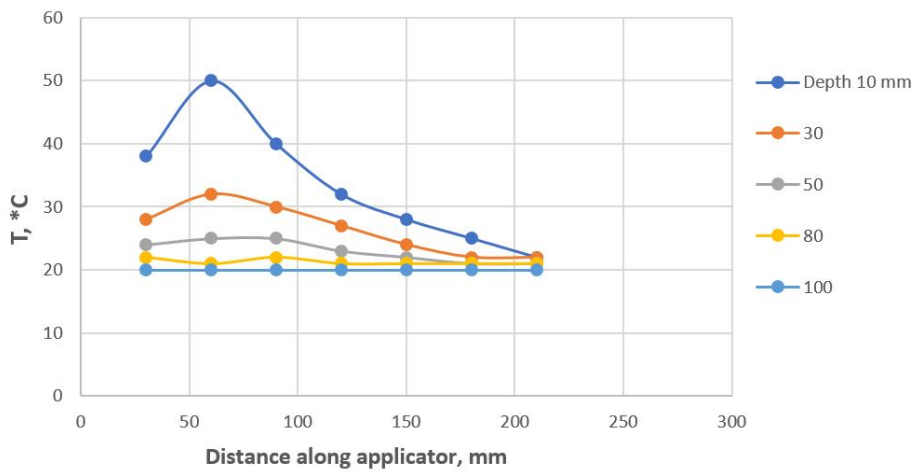

Fig. 4. Temperature distribution in the soil along the comb applicator central plane at $\mathrm{F}=2.45 \mathrm{GHz}, \mathrm{P}=3.5 \mathrm{~kW}$, duration of $\mathrm{MW}$ heating $15 \mathrm{sec}, \mathrm{To}=20^{\circ} \mathrm{C}$, applied energy $53 \mathrm{~kJ}$. Moisture content $\mathrm{MC}=174 \%$, density $1070 \mathrm{~kg} / \mathrm{m}^{3}$.

Maximum energy absorption takes place at a distance of about $60 \mathrm{~mm}$ from the beginning of the applicator. Almost all of the energy was absorbed at the distance of $200 \mathrm{~mm}$ along the applicator for all of the tested soil moisture contents. Maximum energy release takes place in the zone between 60 to $90 \mathrm{~mm}$ from the applicator beginning.

Practically all energy irradiated by applicator was absorbed at the width of about $150 \mathrm{~mm}$ across the applicator. This was consistent across different moisture content of the soil samples. 
Temperature distribution in the central plane of the comb applicator at soil depth between 10 and $100 \mathrm{~mm}$ is illustrated by Fig. 5 .

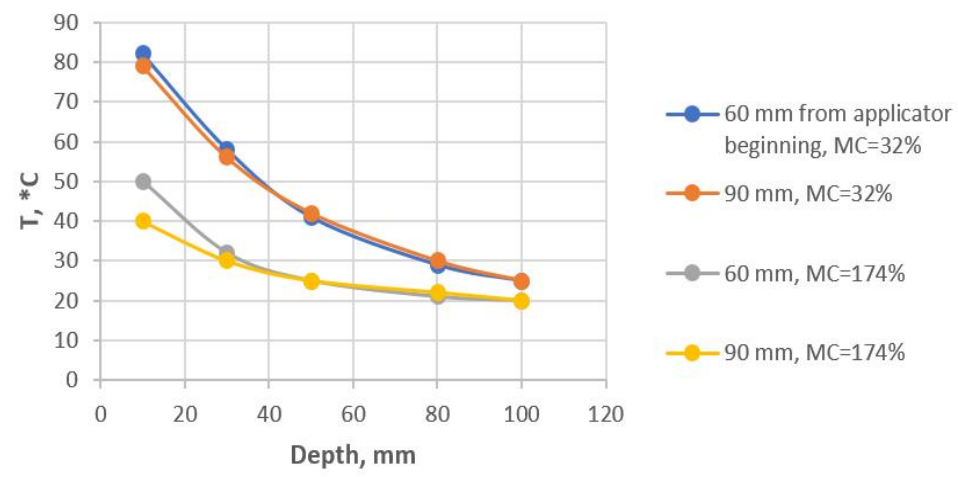

Fig. 5. Temperature distribution in the central vertical plane of the comb applicator at soil depth between 10 and $100 \mathrm{~mm}$ after heating. $\mathrm{MC}=32$ and $174 \%, \mathrm{~F}=2.45 \mathrm{GHz}, \mathrm{P}=3.5 \mathrm{~kW}$, time of MW heating $15 \mathrm{sec}, \mathrm{To}=21^{\circ} \mathrm{C}$.

The most significant part of the energy is absorbed by the soil, with moisture content in the range 32 to $174 \%$, up to the depth of $50 \mathrm{~mm}$ measured in the central vertical plane of the comb applicator. In other volume zones of the soil the share of energy absorbed by surface layers is higher. Almost all of the energy is absorbed at applicator length $200 \mathrm{~mm}$ and width $150 \mathrm{~mm}$ covering soil surface $300 \mathrm{~cm} 2$.

\section{Temperature distribution in the soil by ceramic applicator}

Ceramic block with $3 \mathrm{~mm}$ ceramic plates on the top forms ceramic applicator with thickness $16 \mathrm{~mm}$ from alumina (99\%) material with dielectric parameters: $\mathrm{DC}=9.8$, loss tangent 0.0002. When microwaves travel through alumina they reduce in wave length.

The wave length in the material (ceramics):

$$
\lambda=\lambda_{0} / \sqrt{\dot{\varepsilon}},
$$

where $\lambda_{0}$-wavelength in vacuum (or in air) and

$\dot{\varepsilon}$ - dielectric constant of material.

In our case at $2.45 \mathrm{GHz}$ wave length is $122 \mathrm{~mm}$ and at $\dot{\varepsilon}=9.8$ the wave length in alumina is $\lambda=122: 3.13=40 \mathrm{~mm}$.

This means a wave length in ceramic block is about $40 \mathrm{~mm}$ and microwaves in the ceramics will provide two energy maximums (peak volumes) on the applicator width (comb applicators provide one maximum because wave length in it is $122 \mathrm{~mm}$ ).

Fig. 6 shows typical temperature distribution in the soil at the depth of $10 \mathrm{~mm}$ by ceramic applicator after applying MW power $3.5 \mathrm{~kW}$ for $15 \mathrm{sec}$. 


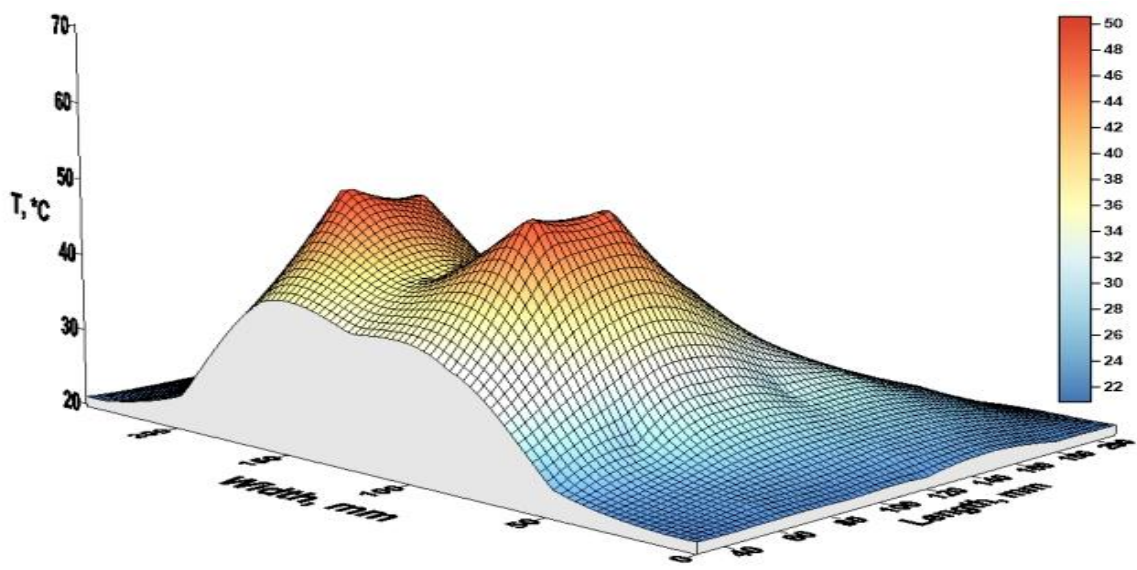

Fig. 6. Temperature distribution in the soil at the depth of $10 \mathrm{~mm}$ by ceramic applicator after MW heating at $\mathrm{F}=2.45 \mathrm{GHz}, \mathrm{P}=3.5 \mathrm{~kW}$, time of $\mathrm{MW}$ heating $15 \mathrm{sec}$, To $=20^{\circ} \mathrm{C}$. Soil moisture content $89 \%$, density $710 \mathrm{~kg} / \mathrm{m}^{3}$.

Temperature distribution along ceramic applicator in the peak vertical plane $(38 \mathrm{~mm}$ from central vertical plane) is shown in Fig. 7 (left).
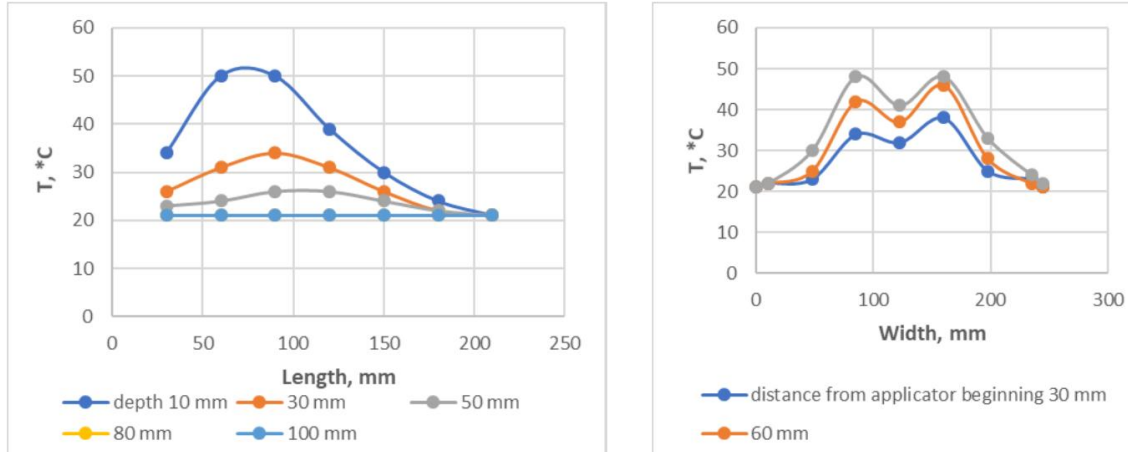

$\rightarrow$ distance from applicator beginning $30 \mathrm{~mm}$

$-60 \mathrm{~mm}$

$-90 \mathrm{~mm}$

Fig. 7. Left. Temperature distribution along ceramic applicator in the peak vertical plane (38 mm from central plane) at different depths after MW heating of the soil with moisture contents $89 \%$. Right. Temperature distribution across ceramic applicator at the depth of 10 mm after MW heating soil with moisture contents $32 \%$. $\mathrm{F}=2.45 \mathrm{GHz}, \mathrm{P}=3.5 \mathrm{~kW}$, time of $\mathrm{MW}$ heating $-15 \mathrm{sec}, \mathrm{To}=21^{\circ} \mathrm{C}$.

For soil $\mathrm{MC}=89$ and $174 \%$ practically all energy is absorbed at the applicator length of 200 $\mathrm{mm}$. For soil $\mathrm{MC}=32 \%$ energy spreads along all of the applicator length. The temperature distribution in a soil sample with $\mathrm{MC}=32 \%$ across the applicator after $\mathrm{MW}$ heating is displayed in Fig.7 (right). Temperature curves show two peaks at a distance of $40 \mathrm{~mm}$ on each side of the central vertical applicator plane and lowest at the applicator central vertical plane.

Temperature distribution in the peak vertical plane of the ceramic applicator at soil depths and $\mathrm{MC}=32,89$ and $174 \%$ is shown in Fig. 8 . 


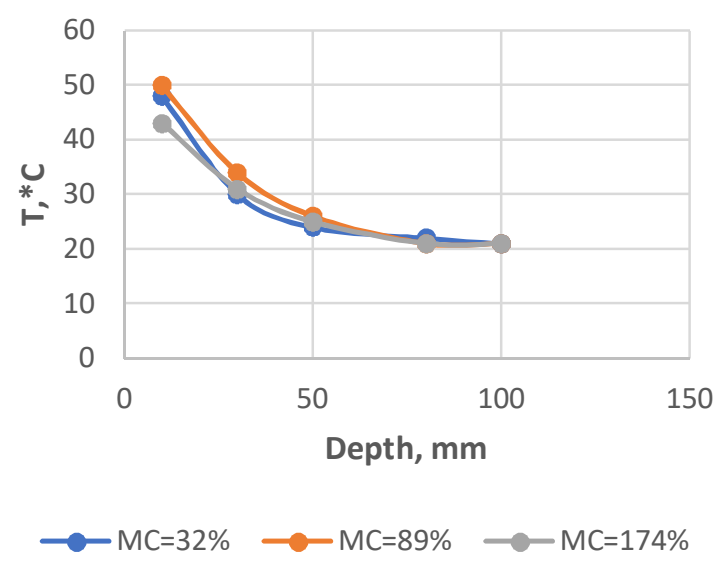

Fig. 8. Temperature distribution by the soil depths at the peak vertical pane of the ceramic applicator at the distance of $90 \mathrm{~mm}$ from applicator beginning after heating and $\mathrm{MC}=32$, 89 and $174 \% . \mathrm{F}=2.45 \mathrm{GHz}, \mathrm{P}=3.5 \mathrm{~kW}$, time of heating $15 \mathrm{sec}, \mathrm{To}=21^{\circ} \mathrm{C}$.

The most significant part of the energy is absorbed by the soil at the peak vertical planes on the depth up to $50 \mathrm{~mm}$, and practically all of the energy is absorbed at the depth up to 80 $\mathrm{mm}$. In other volumes of the soil the share of energy absorbed by surface layers is higher.

\section{Comparison of the temperature distribution in the soil by comb and ceramic applicators}

Fig. 3 with one temperature peak and Fig. 6 with two temperature peaks illustrate principal difference in energy distribution in the soil by comb and ceramic applicators. Comb applicator provides maximum soil heating in the central vertical applicator plane because the transporting electromagnetic wavelength is $122 \mathrm{~mm}$. Alumina ceramic block transforms electromagnetic wave from $122 \mathrm{~mm}$ to the wavelength of $40 \mathrm{~mm}$ and provides a different pattern of energy distribution in the soil with two peaks in the vertical cross planes. Fig. 9 illustrates the difference of temperature distribution in a soil sample at the vertical cross section of the two applicators. 


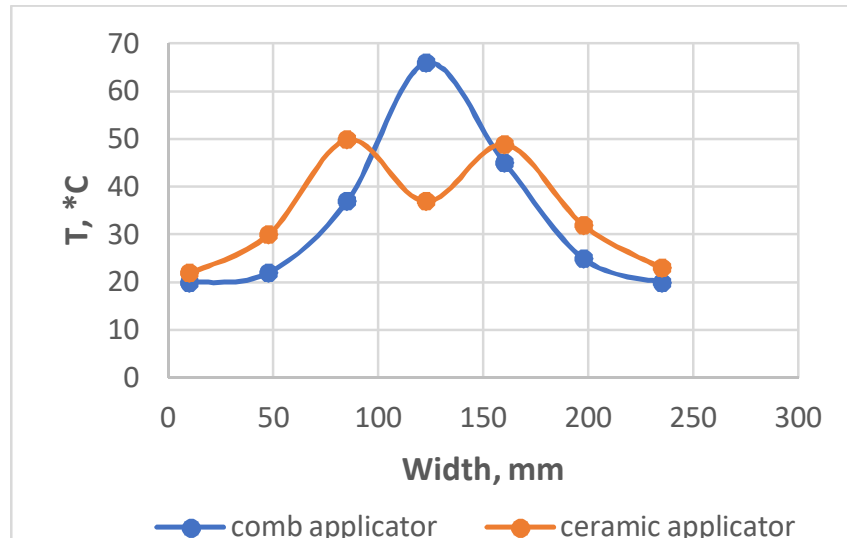

Fig. 9. Temperature distribution across comb and ceramic applicators at the soil depth of $10 \mathrm{~mm}$ and distance of $90 \mathrm{~mm}$ from applicator beginning after MW heating of the soil with moisture contents $89 \%$. $\mathrm{F}=2.45 \mathrm{GHz}, \mathrm{P}=3.5 \mathrm{~kW}$, time of MW heating $15 \mathrm{sec}, \mathrm{To}=21^{\circ} \mathrm{C}$.

Peak temperature in the soil provided by the ceramic applicator is significantly lower compared to peak temperature provided by the comb applicator. This reduces overheating of the soil surface and energy losses. Test results of comb and ceramic applicators in similar conditions are shown in Table 2.

Table 2. Test results of comb and ceramic applicators for frequency $2.45 \mathrm{GHz}$.

\begin{tabular}{|l|l|c|c|}
\hline Items & Units & Comb applicator & Ceramic applicator \\
\hline $\begin{array}{l}\text { Soil moisture content and } \\
\text { density }\end{array}$ & & \multicolumn{2}{|c|}{$\mathrm{MC}=32-174 \%$, density $586-1070 \mathrm{~kg} / \mathrm{m}^{3}$} \\
\hline $\begin{array}{l}\text { Majority of the applied MW } \\
\text { energy was absorbed: }\end{array}$ & $\mathrm{mm}$ & $200-210$ & $\begin{array}{c}200(\mathrm{MC}=89-174 \%) \\
350(\mathrm{MC}=32 \%)\end{array}$ \\
\hline on the applicator length & $\mathrm{mm}$ & 150 & $200-210$ \\
\hline on the applicator width up to & $\mathrm{mm}$ & $100-130$ & 80 \\
\hline on the material depth up to & $\mathrm{mm}$ & 30 & 70 \\
\hline $\begin{array}{l}\text { Length of zone of high intensity } \\
\text { heating along applicator } \\
\text { (distance from applicator } \\
\text { beginning) }\end{array}$ & & & 60 to 90$)$ \\
\hline $\begin{array}{l}\text { Average MW specific energy } \\
\text { applied to the soil }\end{array}$ & $\mathrm{kJ} / \mathrm{cm} 2$ & 0.18 & 0.13 \\
\hline
\end{tabular}

Measuring the maximum degree of non-uniformity of the temperature in the soil by ratio of peak temperatures to initial temperatures, the comb applicator provides non-uniformity 3.1 , ceramic applicator -2.3 . 
The ceramic applicator provides better uniformity of energy distribution on the width of the applicator due to two temperature peaks. In addition, depth of energy penetration is lower. This means the ceramic applicator provides more energy absorption within the soil surface layers compared to comb applicator and therefore is more effective. For practical use, instead of ceramic block (thickness $13 \mathrm{~mm}$ ) + ceramic plates (thickness $3 \mathrm{~mm}$ ), it is better to use one alumina ceramic block with thickness of $16 \mathrm{~mm}$.

To improve the uniformity of the energy distribution by ceramic applicators it can be recommended to use ceramics with higher dielectric constant 15-25 (PD- 15, PD-20, PD25). This creates 3 or $4 \mathrm{MW}$ power peaks along the applicator width keeping the energy closer to the applicator surface. This will increase efficiency of MW energy use.

In terms of effective energy use for thermal treatment and sterilization of soil surface layers, using a ceramic applicator has the following advantage compared to a comb applicator:

- better uniformity of energy distribution on the width of the applicator,

- better energy localization in the soil surface layers,

- the soil moisture content in the range between $32-174 \%$ does not have a significant effect on energy localization in the surface layers.

Ceramic applicators can be recommended for practical use in machines for thermal treatment and sterilization of the soil and other materials surface layers.

\section{Conclusion}

Comb applicator provides maximum energy release into the soil at the central vertical plane. Ceramic applicator from alumina forms two temperature peaks in the vertical planes at a distance of about $40 \mathrm{~mm}$ each side of the central applicator plane and minimum in the applicator central plane. Ceramic applicator provides better uniformity of the energy distribution along the width of the applicator due to two temperature peaks. The depth of energy penetration is lower compared to comb applicator. Thus, the ceramic applicator provides better energy localization and more energy absorption in soil surface layers compared to a comb applicator. To provide better uniformity of energy distribution across ceramic applicator it is recommended to use ceramics with higher dielectric constant. Using ceramics with dielectric constant of 15-25 would provide 3 or 4 temperature peaks on the applicator width, keeping more energy closer to the applicator surface. This will increase efficiency of MW energy use.

The ceramic applicator is more effective for MW treatment of the soil surface areas and is recommended for practical use in machines for thermal treatment and sterilization of surface layers of the soil and other materials.

\section{References}

1. Pchelnikov Yu. N. Features of slow waves and potentials for their nontraditional application. J. of Communications Technology and Electronics, 2003, Vol 48, (4), 450-462.

2. Pchelnikov Yu. N. SWS - based applicators for agriculture application.

Unpublished Report of Company "Pchelnikov Consulting" for Melbourne University. 2014, pp 39.

3. Silin R. A. Periodic Waveguides. Fazis, Moscow, 2002, [in Russian].

4. Watkins D. A. Topics in Electromagnetic Theory. Willy \& Sons Inc., N.Y.,1958.

5. Yelizarov A. A., Pchelnikov Yu. N. Radio-Wave Elements of Technological Devices and Equipment on Slow-Wave Structures. Radio and Communication, Moscow, 2002, [in Russian]. 